\title{
Interpretasi dan Bentuk Penyajian Lagu "Habanera" dalam Opera Carmen Karya George Bizet Oleh Heny Janawati
}

\author{
Salma Falista Salsabilla \\ Program Studi Seni Musik, Fakultas Bahasa dan Seni, Universitas Negeri Surabaya \\ e-mail: salmafalistanew@gmail.com
}

\begin{abstract}
Habanera, one of the most famous songs in Opera Carmen, tells the love life of Carmen as the main role. Interestingly, the song Habanera was sung by an Indonesian mezzo-soprano singer from Bali, Heny Janawati, who has perform the Opera Carmen while singing in Europe and Indonesia with different interpretations and performance of song Habanera. The purpose of this study was to analyse the interpretation and performance form of the Habanera Opera Carmen song when it was performed in Jakarta in 2016 in order to become a knowledge. This research process used qualitative methods. The data in this study were obtained through observation, interviews, and documentations. Data analysis techniques used data reduction, data presentation, and data inference. As for the data validity test used triangulation. The results of this study indicate that Heny Janawati has characteristics to interpret this song throughout the structure, tempo, dynamics, and intonation of this song. That she present in Opera Carmen are more modern from its Europe counterpart, which in Europe its characteristics, number of accompaniments, dimensions of the setting, lighting and wardrobe are more traditional.
\end{abstract}

Keywords: Interpretation, Performance Form, Habanera Songs, Heny Janawati

\begin{abstract}
Abstrak: Lagu Habanera salah satu lagu terkenal dalam Opera Carmen, menceritakan kehidupan cinta Carmen sebagai peran utama. Menariknya, lagu Habanera pernah dinyanyikan oleh seorang penyanyi mezzo-sopran Indonesia asal Bali yaitu Heny Janawati yang pernah menyajikan Opera Carmen di Eropa dan di Indonesia dengan interpretasi dan penyajian berbeda. Tujuan penelitian ini untuk menganalisis interpretasi dan bentuk penyajian pada lagu Habanera Opera Carmen saat ditampilkan di Jakarta tahun 2016 sebagai pengetahuan. Proses penelitian ini menggunakan metode kualitatif. Data dalam penelitian ini diperoleh melalui observasi, wawancara, dan dokumentasi. Teknik analisis data menggunakan reduksi data, penyajian data, dan penyimpulan data. Adapun uji keabsahan data menggunakan triangulasi. Hasil penelitian ini menunjukkan Heny Janawati memiliki ciri khas untuk menginterpretasikan lagu ini melalui struktur lagu, tempo, dinamika, intonasi dalam membawakannya. Penyajian Opera Carmen ini berbeda dengan di Eropa, dari karakteristik, jumlah pengiring, dimensi setting, tata cahaya dan rias busana berbeda dengan tradisonal Eropa sedangkan di Indonesia lebih modern.
\end{abstract}

Kata Kunci: Interpretasi, Bentuk Penyajian, Lagu Habanera, Heny Janawati.

\section{PENDAHULUAN}

Saat ini perkembangan musik di berbagai masyarakat semakin luas. Secara umum musik mempunyai berbagai warna yang dimana masing-masing mempunyai keunikan sendiri. Musik adalah seni yang berbicara tentang berbagai suara ke dalam pola-pola yang dapat dimengerti dan dipahami manusia. Musik adalah bunyi nyata, yang bisa diperlihatkan dalam dimensi ruang dan waktu, serta menerapkan sebuah kedisiplinan yang harus diterapkan, kedisiplinan tersebut mencakup solfeggio (pendengaran musik) dan teknik bermain musik. Pada era pandemi seperti sekarang ini, musik sangat sulit untuk diterapkan atau dilatih secara langsung sehingga dituntut untuk disiplin penuh bagi mereka yang di bidang musik melewati prosesnya. "Learning activities, where students listen to their friends while singing and then imitate themselves" (Dharmawanputra, Murbiyantoro, Karyawanto 2020 : 806) dalam teori tersebut menjelaskan bahwa mereka yang berlatih dalam bidang musik terutama vokal berlatih dengan metode solfeggio atau pendengaran melewati bunyi antar teman mereka sambil bernyanyi lalu menirukan diri mereka sendiri yang harus sesuai dengan partitur dan bunyi yang diterapkan. Bunyi adalah bahan dasar keberadaan musik, musik adalah pengaturan bunyi (Dankworth, 1978). Musik juga memiliki unsur seperti melodi, harmoni, ritme, tempo, dinamika, dan lirik yang disusun 
sehingga menjadi sebuah lagu. Lagu merupakan karya musik untuk dinyanyikan atau dimainkan dengan pola dan bentuk tertentu (Banoe, 2003). Lagu menjadi bagian yang integral dari pengalaman berbahasa manusia (Schoepp, 2001). Lagu mempunyai ritme dan melodi yang teratur dan lagu bisa menjadi curahan hati setiap pencipta dan penikmat lagu itu sendiri. Lagu bisa menjadi sebuah ungkapan kehidupan pada setiap manusia dan bisa dikenang dari bentuk ritme, melodi atau lirik yang ada pada lagu yang didengar atau diciptakan. Salah satunya dalam penelitian ini adalah lagu karya George Bizet.

George Bizet adalah seorang komposer pada Era Romantik yang lahir pada 25 Oktober 1838. George Bizet meninggal diusia 36 tahun pada 3 Juni 1875 . Komposer asal Prancis ini menciptakan beberapa komposisi lagu yang dibawakan di dalam Opera Carmen.

Opera Carmen merupakan suatu penyajian opera klasik di era Romantik dengan iringan musik dan vokal karya komposer asal Prancis yaitu George Bizet. Opera dengan empat babak ini pertama kali dipentaskan di Paris pada tahun 1875. Dalam Opera Carmen menceritakan kisah tragis perebutan hati wanita gipsi yang menjadi pusat perhatian para lelaki karena pesonanya membuat seakan seluruh dunia hanya tertuju padanya. Namun tak sesuai mimpi Carmen, menjadi wanita penuh pesona juga bisa menjadi malapetaka. Carmen terlibat dalam cinta segitiga karena itu membuatnya disebut wanita yang memainkan hati banyak lelaki. Pesona Carmen membuat Don Jose sang Kopral jatuh hati pada Carmen hingga mereka berdua menjadi sepasang kekasih. Namun Carmen tergoda dengan lelaki lain, Carmen juga menerima Escamillo seorang Toreador untuk menjadi kekasih gelapnya. Akibat terlibat dalam cinta segitiga, Carmen dibunuh oleh kekasihnya Don Jose di pabrik rokok karena Don Jose merasa cintanya dikhianati oleh Carmen dan membuatnya merasa kecewa.

Dari beberapa lagu yang dibawakan dalam opera carmen, terdapat salah satu lagu yang dikenal yaitu lagu Habanera. Lagu ini dinyanyikan oleh Carmen pada adegan lima di babak pertama. Pada adegan lima dibabak pertama lagu Habanera ini menceritakan tentang Carmen yang dapat membutakan cinta seseorang. Carmen yang lebih kuat, juga secara dramatis lebih meyakinkan karena Sebagian paduan suara, terutama dimana orang kepercayaan Carmen yaitu Frasquita dan Marcedes serta orang disekitarnya, "Bergabunglah!" dengan seruan Carmen tentang cinta bebas yang merupakan inti dari aria (Bizet George, 2018).

Lagu Habanera pernah dinyanyikan oleh satu-satunya penyanyi opera asal Indonesia yang pernah membawakan opera carmen di Indonesia dan di Eropa. Di Indonesia hampir jarang ditemui penyanyi mezzo-soprano yang bisa bernyanyi secara klasik dan bisa menyajikan vokal di pertunjukkan opera itu dengan baik seperti Heny Janawati, selain itu minat vokal opera di Indonesia juga hampir tidak sering ditemui. Sejak tahun 2004 nama Heny Janawati sudah terkenal dengan penyanyi klasik dan opera. Heny Janawati satu-satunya yang menyanyikan lagu Habanera dalam memerankan "Carmen" di Indonesia. Selain di Indonesia, Heny Janawati juga pernah memerankan Opera Carmen di Eropa yaitu di Canada dalam acara Bard On The Beach Festival dan di Ceko dalam acara European Music Academy (Czech Republic) dan pertama kali memerankan Carmen dalam Opera Carmen di Ceko. Heny Janawati berpendapat, butuh waktu latihan dua setengah bulan dengan diadakannya audisi terlebih dahulu agar bisa memerankan Carmen di Ceko dengan baik, hal ini diwawancara oleh CNN Indonesia pada tahun 2016 seusai Heny Janawati pentas Opera Carmen Bersama Jakarta Concert Orchestra dengan Avip Priatna sebagai Konduktor sekaligus Direktur Musik Opera Carmen di Ciputra Theater, Ciputra Artpreneur, Kuningan, Jakarta Selatan.

Opera Carmen seringkali dibawakan Heny Janawati dalam acara apapun, salah satunya lagu yang dibawakan Heny Janawati dalam Opera Carmen berjudul Habanera memiliki teknik vokal yang menjadi salah satu keunggulan Heny Janawati saat menyanyikannya. Menurut Heny Janawati sendiri mengaku sangat senang memerankan Carmen dan salah satu lagu favorit Heny Janawati dalam Opera Carmen sendiri adalah lagu Habanera. Heny Janawati merasa tertantang untuk memerankan sosok yang bisa dibilang liar namun tetap memiliki kebaikan dalam dirinya. Hobby Heny Janawati berada di musik klasik terutama vokal opera dan art song serta membaca buku-buku novel klasik karya-karya Jane Austeen. Alasan Heny Janawati suka dunia opera adalah sejak kecil Heny Janawati memang 
menyukai seni vokal klasik, namun karena akses pelatihan vokal saat itu belum memungkinkan di Bali, Heny Janawati belajar dari ayahnya yaitu Alm. IGB Ngurah Ardjana, yang juga seorang seniman dan penulis lagu Bali ternama yang banyak menginsiprasi Heny Janawati itu sendiri.

Selain itu, Heny Janawati juga banyak berkencimpung di dunia Theatre di sekolah dan sangat menyukai seni peran. Pada suatu hari, Heny Janawati tanpa sengaja menemukan sebuah kaset yang berisikan sebuah kaset yang berisikan lagu-lagu opera yang dinyanyikan oleh soprano ternama di dunia, Madam Maria Callas yang tak lain adalah penyanyi asli dari lagu Habanera. Saat itu, Heny Janawati belum memahami bahwa Madam Maria Callas adalah The Diva Of Opera, namun Heny Janawati sangat jatuh cinta dengan suara Madam Maria Callas yang sangat expressive bahkan mampu membuat Heny Janawati menangis walaupun Heny Janawati waktu itu tidak mengerti apa yang dinyanyikan oleh Madam Maria Callas.

Heny Janawati jatuh cinta dengan opera walaupun menurut Heny Janawati rasanya untuk belajar opera saat itu hanyalah sebuah mimpi. Namun akhirnya Heny Janawati mendapat jalan untuk belajar opera di Negara Kanada. Teknik vokal pada lagu Habanera tergolong teknik yang susah khususnya untuk seorang penyanyi yang ingin belajar vokal klasik khususnya di vokal klasik opera. Lagu Habanerapun juga digunakan saat ujian Mayor Vokal Akhir semester enam di Prodi Musik Universitas Negeri Surabaya sehingga perlu adanya pemantapan mengenai teknik vokal dalam lagu sehingga dapat dinyanyikan dengan baik. Ini menjadi alasan mengapa peneliti memilih judul "Interpretasi dan Bentuk Penyajian Pada Lagu Habanera Dalam Opera Carmen Karya George Bizet oleh Heny Janawati. Banyak hal yang menarik di dalam opera carmen terutama pada lagu Habanera. Hasil penelitian atau pembahasan ini diharapkan dapat bermanfaat untuk memberikan sumbangan pengetahuan terhadap masyarakat penikmat lagu klasik dan untuk penyanyi klasik yang akan membawakan atau belajar vokal opera khususnya di lagu Habanera.

\section{METODE}

Metode penelitian pada dasarnya merupaka cara ilmiah untuk mendapatkan data dengan tujuan dan kegunaan tertentu (Sugiyono, 2017). Deskriptif analisis merupakan suatu metode penelitian yang mengungkapkan tentang obyek dalam bentuk deskriptif yang disertai analisis terhadap segala sesuatu melalui pendekatan yang telah ditentukan.

Bentuk penelitian ini menganalisis lagu yang dinyanyikan oleh subjek penelitian dengan metode kualitatif. Menganalisis lagu melalui interpretasi yang dibawakan dan bentuk penyajian yang disajikan, mengungkapkan bahwa interpretasi dan bentuk penyajian lagu meliputi: Struktur lagu, tempo, dinamika, intonasi yang dinyanyikan. Mentranskripsikan unsur-unsur lagu pada dasarnya adalah mengalihkan unsur-unsur tersebut dari bentuk video dan wawancara ke dalam bentuk visual atau tulisan". Penggunaan dua proses transkripsi merupakan pendekatan yang penting, dengan membuat analisis sementara serta mendeskripsikan apa yang kita dengar dan lihat kemudian menuliskannya diatas kertas (tentang lagu yang didengar dan dilihat) hal ini disebut sebagai proses dalam pengumpulan data. Hasil dari pengumpulan data tersebut kemudian divalidasi dengan teknik validitas data berupa wawancara, dan metode triangulasi.

\section{HASIL PENELITIAN DAN PEMBAHASAN}

\section{Deskripsi dan Bentuk Lagu Habanera dalam Opera Carmen Oleh Heny Janawati}

Penyanyi asli Lagu Habanera adalah Maria dan dalam Opera Carmen, lagu Habanera dinyanyikan oleh peran utama yaitu Carmen pada adegan lima di babak pertama. Menurut Kertesz dan Christoforidis, habanera berasal dari bentuk rakyat di Kuba multi-etnis, tetapi di Eropa itu menjadi tarian pergaulan, bentuk urban Spanyol yang populer dan favorit di kalangan aristocrat salon Kekaisaran kedua Prancis, dimana itu dengan jelas menunjukkan Bahasa Spanyol (2008:102). Lagu Habanera ini memikat para komponis Eropa termasuk Bizet, yang dengan cerdas memasukkan gaya musik dalam opera-nya. Dalam hal ini, Habanera dinyanyikan oleh Heny Janawati dalam penyajian Opera Carmen di Jakarta dengan pimpinan Avip Priatna selaku Direktur Musik dan Konduktor Jakarta Concert Orchestra. Habanera dalam Opera Carmen dinyanyikan pada adegan lima dibabak pertama Habanera ini menceritakan tentang Carmen yang dapat membutakan cinta pada semua yang jatuh hati 
padanya, ada ekspresi riang ada juga cinta dengan emosi yang membara didalamnya. Jenis lagu habanera ini adalah lagu Havana atau lagu tarian di Spanyol yang menceritakan tentang carmen itu sendiri. Ciri khas lagu ini melodi kromatiknya yang menjuru seperti tangga nada, memiliki repeat di chorus yang hanya beda di coda, repeationnya memiliki referensi pemakaian skala kromatik dari lagu El Allegretto. Selain skala kromatik, ciri khas Habanera juga berdasarkan cubanes form rytem dari cuba, dance musik cuba. Awal mula publikasi Habanera ini 3 Maret 1975 oleh Maria Callas, sedangkan Heny Janawati pertama kali memerankan Opera Carmen khususnya menyanyikan Habanera di dalam bagian episode Carmen tahun 2009 dengan Republic Ceko di Ustei Nad Labem pada tanggal 4 Juli 2009 dengan dua kali casting, nama festival tersebut Bard On The Beach. Perkembangan habanera masa ke masa berinterpretasi semakin bebas tergantung director. Nada dasar Habanera adalah D Minor, memiliki pengulangan motif kalimat tanya dan kalimat jawab dengan Ending D Major dan memiliki nada tertinggi di F Sharp, disajikan dengan iringan piano dan backing vokal paduan suara Sopran, Tenor, Bass. Lagu Habanera terdapat 120 birama.. Bentuk musik lagu Habanera adalah "rondo" yang artinya adalah mengulang. Bentuk musik "rondo" dikuasai oleh prinsip Kembali kepada lagu semula setelah mengalami lagu yang berlainan (Prier, 2017). Jika dijelaskan dalam bentuk huruf, lagu Habanera terdapat motif A-A'-B setiap tema terdapat pengulangan nada namun perbedaannya terletak pada lirik, tema A menggunakan D Minor dan tema B menggunakan D Major dengan repeat.

\section{Interpretasi Lagu Habanera Menurut Partitur oleh Heny Janawati}

Interpretasi dalam musik terutama vokal merupakan sebuah penghayatan lagu yang diartikan dalam diri sendiri melalui ekspresi sesuai yang diminta oleh composer dan pengembangan dari diri sendiri. Tentunya untuk memainkan karya musik dengan baik, sudah seharusnya memahami karya komponis dengan baik sehingga perlu dilakukan interpretasi, agar pesan komponis dapat tersampaikan ke penonton. (Nurcahyo, 2018:6). Interpretasi sangat berkaitan dengan chemistry terutama pemain atau penyanyi dengan komposer lalu disampaikan kepada pendengar. Antara komponis dan karyanya dengan pemain dan alatnya, terletak suatu jarak hubungan dramatis yang tiada habis-habisnya (Hardjana, 2002: 115).Habanera dinyanyikan oleh peran Carmen adalah sebuah lagu yang diartikan bahwa Habanera adalah narasi cinta menurut Carmen yang cantik dan bebas dengan ekspresi Carmen yang santai menggoda dan sedikit sombong dengan kecantikannya.

Struktur Cerita lagu Habanera di setiap lirik yang ditulis sendiri oleh George Bizet yaitu arti dalam bar 4-8 bahwa cinta yang dimaksud Carmen sebuah kebebasan mencintai siapapun yang Carmen inginkan, bar 8-12 mengartikan Carmen wanita yang tidak dapat dicegah, apa yang dia mau dia harus mendapatkannya, bar 12-16 mengartikan Carmen menceritakan tentang dirinya sendiri yang merasa dirinya sempurna dari wanita lain, bar 16-20 mengartikan Don Jose seolah sudah membutakan hati Carmen sehingga Carmen tidak membuang pandangan sama sekali dengan Don Jose., bar 21-26 artinya adalah "Cinta", disini Carmen mengatakan cinta dengan rasa senang dan sikap menggoda, bar 28-44 artinya Bohemia yang dimaksud adalah Don Jose, Carmen jatuh cinta pada pria yang tidak mencintainya terlebih dahulu hati seluruh pria, bar 44-53 bagian dari paduan suara yang menjadi backing vocal mengulang arti dari bar 28-44 solo Carmen, bar 53-61 mengulang arti dari bar 37-44 dengan solo Carmen, bar 64-80 artinya Carmen mendeskripsikan bahwa dia seperti burung, memiliki sayap, dia bisa mengepakkan sayapnya dan terbang jauh dia bebas mencari apa yang dia inginkan termasuk cintanya, bar 81-120 mengulang dan sama seperti bar 21-60. Nada dasar pada lagu Habanera adalah D (minor) menggunakan tangga nada $1 \mathrm{~mol}$ (b) dan akhir lagu juga ada di D (major). Pada birama 20 dan 75 seakan-akan modulasi namun awal sampai akhir lagu tidak ada modulasi.

Terdapat beberapa tempo yang digunakan dalam lagu Habanera adalah allegreto, quasi andantino. Menurut Heny Janawati dapat dijabarkan bahwa pengertian tempo tersebut ialah allegro yang hampir ke andantino, yang 
artinya cepat namun sedikit melambat. Tempo berkisar $72 \mathrm{bpm}$ dan memiliki sukat 2/4. Ada sedikit accent (hentakan) pada notasi awal birama 37,53,97, 113 meskipun berdinamikan $\mathrm{p}$ (piano) dan pp (pianossimo) (wawancara, Janawati 4 Desember 2020).

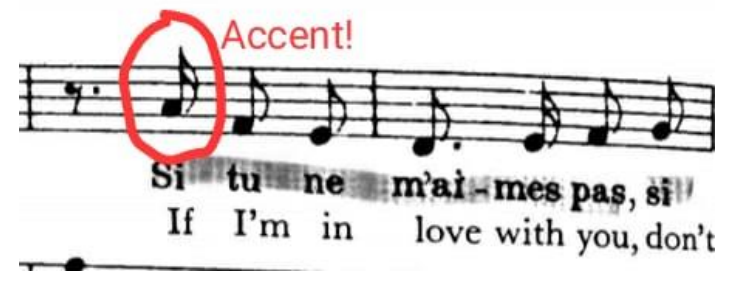

Gambar 1. Accent di birama 37.

Sumber gambar: G. Schimer, Inc. Ciptaan : George Bizet

Pada birama 43-44 dan birama 103-105 di awal notasi, narasumber memakai tempo ritardando yang artinya tempo lebih melambat dan ditahan untuk menambah ornament tempo sekaligus untuk mempermanis lagu dan pemenggalan nafas.

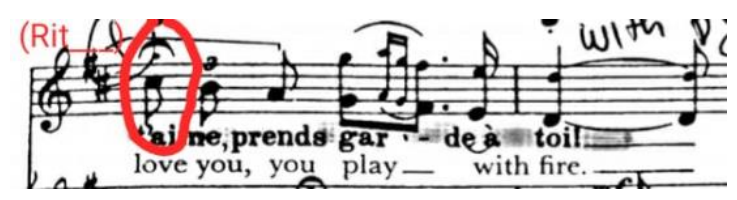

Gambar 2. Rit/Ritardando di birama 43-44.

Sumber gambar : G. Schimer, Inc. Ciptaan : George Bizet

Lagu Habanera memiliki tanda fermata di beberapa birama. Fermata adalah tanda tempo yang mengharuskan penyanyi untuk menghentikan hitungan sementara kemudian dilanjut lagi, bila ada tanda fermata terdapat di atas sebuah nada, maka nada itu yang ditahan, bila tanda fermata terdapat diatas tanda istirahat, maka istirahat itu yang ditahan, bila tanda fermata terdapat diatas garis/birama/sukat, maka antara birama sebelumnya dan birama berikutnya disisipkan waktu "kosong" (Prier, 2011:45). Pada partitur yang dibahas, penyanyi (narasumber) menggunakan fermata untuk mengekspresikan dirinya solo/acapella tanpa iringan musik dengan menahan nada sepanjang yang di inginkan oleh penyanyi itu sendiri. Contoh pada birama 43 terdapat tanda fermata di notasi awal. Lalu dilanjut dengan fermata pada birama 59 dam 103. Pada gambar dibawah ini salah satu contoh pada notasi fermata pertama di birama 43.

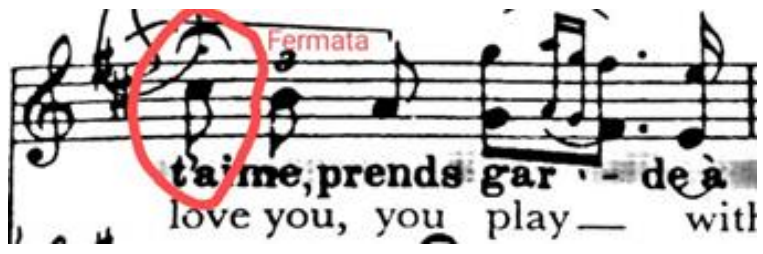

Gambar 3. Contoh tanda fermata pada birama 43. Sumber gambar : G. Schimer, Inc. Ciptaan : George Bizet

Lagu Habanera juga memiliki tanda triol. Triol adalah satu nada utuh dapat diganti dengan dua nada setengah dapat diganti dua nada perempat, satu nada perempat dapat diganti dengan dua nada perdelapan dan seterusnya namun bisa satu hitungan (nada seperempat) dibunyikan tiga nada (nada perdelapan) ini disebut triol, terdapat pula triol besar yakni bila selama dua hitungan (satu nada setengah atau dua nada seperempat) dibunyikan tiga nada atau sama seperti dibunyikan dengan nada perempat (Prier, 2011). Dalam partitur lagu Habanera yang digunakan oleh Heny Janawati memiliki triol besar di setiap nada kromatiknya yang ada pada birama 5,9,13,17,43,65,69,73,77,103 di vokal utama dan pada birama 21,25,81,85 di paduan suara. Lagu Hanaera juga memiliki banyak Dinamika (Dynamics) dan Ekspresi untuk menguatkan penyampaian interpretasi pada lagu tersebut. Habanera yang digunakan oleh Heny Janawati memiliki macam-berbagai dinamika dan ekpresi yang membuat lagu tersebut menjadi lebih hidup. Dinamika tersebut ialah piano $(p)$, pianissimo $(p p)$, forte $(f)$, mezzo forte $(m f)$, crescendo (<), decrescendo (>), Portanento. Beberapa ekspresi yang ditampilkan dalam partitur lagu Habanera menurut Heny Janawati pada birama 21 dan 64, penyanyi harus terlihat lebih look sensualy sesuai karakter yang dimainkan, namun secara keseluruhan ekspresi yang ditampilkan ini seperti halnya bercerita santai, sedikit angkuh namun menggoda. Salah satu dinamika dengan istilah Piano yang artinya pela nada pada birama 4 notasi ke dua terdapat dinamika piano yang mengharuskan penyanyi bernyanyi dengan lembut di bridge yang pertama dengan ekspresi sedikit tersenyum dan membinarkan mata berjalan sedikit demi sedikit dengan tatapan mata yang tajam. (wawancara, Heny Janwati 4 Desember 2020). Contoh dinamika Piano birama 4 pada gambar dibawah ini. 


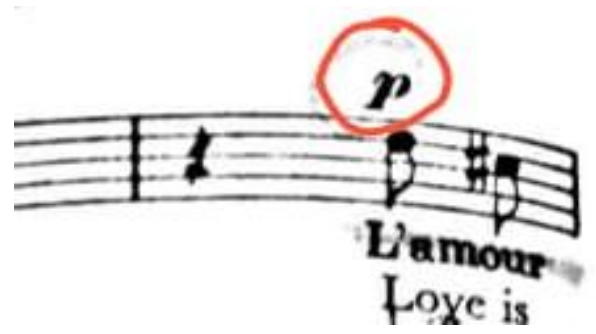

Gambar 4. Dinamika Piano pada birama 4. Sumber gambar : G. Schimer, Inc. Ciptaan : George Bizet

Dalam birama 21-22 dengan dilakukan repeat di birama 81-82 dinamika Piano ditambah sendiri oleh narasumber utama yaitu Heny Janawati untuk memberi tambahan ornament yang akan memperindah dan memberi kesan look sensually sesuai dengan interpretasi dalam lagu Habanera pada bridge birama awal bagian pertama. Beikut dibawah ini contoh dinamika Piano pada birama 21-22

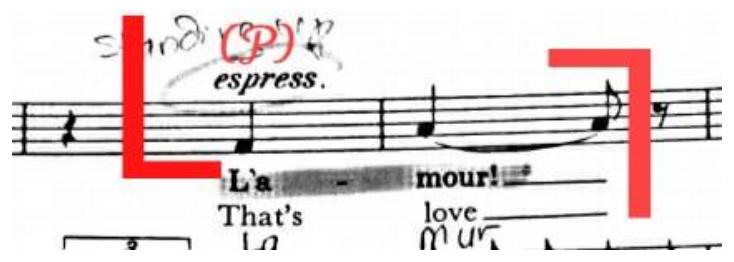

Gambar 5. Dinamika Piano pada birama 21-22 . Sumber gambar: G. Schimer, Inc. Ciptaan : George Bizet

Dalam birama 59 dan birama 119 terdapat dinamika Piano satu birama pada paduan suara yang memnbunyikan satu nada penuh dalam satu birama untuk aba-aba mencapai klimaks sebelum repeat atau dilakukan pengulangan pada empat birama selanjutnya.

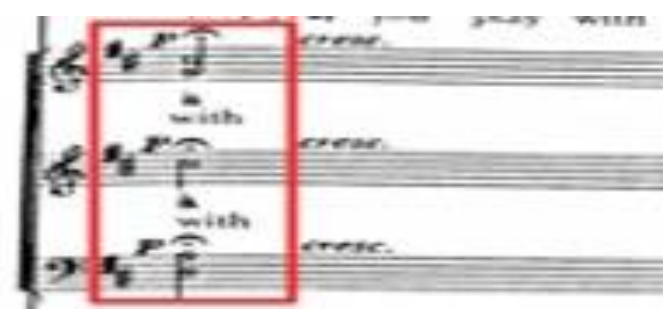

Gambar 6. Letak dinamika Piano pada birama 59. Sumber gambar : G. Schimer, Inc. Ciptaan : George Bizet

Selain piano, juga terdapat dinamika Pianissimo (pp), pianissimo hampir sama dengan piano, namun dinamika pianissimo lebih lembut dari dinamika piano. Pada partitur lagu. Pada partitur Habanera sebenarnya tidak memiliki dinamika pianissimo pada vokal utama dan paduan suara namun narasumber utama juga menambahkan dinamika tersebut untuk memperindah interpretasinya. Letak dinamika pianissimo yang digunakan oleh narasumber utama berada di birama 27-28 pada notasi akhir di birama 27 dan notasi awal di birama 28 , birama 87 pada vokal utama (disusul dengan birama 88 yang memakai dinamika piano pada vokal utama), birama 97-99 (narasumber memakai accent pada temponya namun tetap memakai dinamika pianissimo), lalu ada dinamika pianissimo legato ( $p p$ legg) yang artinya sangat lembut dengan teknik yang terikat pada serangkaian not yang digunakan, dinamika ini ada pada birama 20-28 oleh paduan suara dan dilakukan repeat pada birama 80-88. Pada birama 27 dan birama 28 di bagian pertama memiliki dinamika pianissimo di notasi akhir pada birama 27 dan di notasi awal pada birama 28, dinamika ini ditambah oleh narasumber utama sendiri yaitu Heny Janawati untuk memberi kesan tenang namun tetap berekspresi look sensually untuk menuju ke chorus pada lagu tersebut yang memiliki kesan bercerita, tenang, dan menikmati lagu yang dinyanyikan atau ditampilkan. Contoh dibawah ini letak dinamika pianissimo yang ditambah oleh narasumber yaitu Heny Janawati.

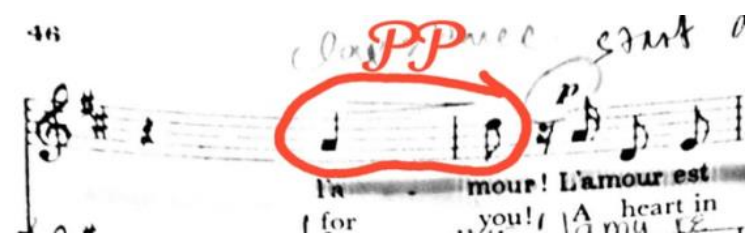

Gambar 7. Birama 27 dengan notasi akhir dan birama 28. Sumber gambar: G. Schimer, Inc. Ciptaan : George Bizet

Berbeda dengan dinamika pianissimo sebelumnya, menurut partiture Habanera pada birama 20-28 ini memiliki dinamika pianissimo leggato yang artinya dinamika tersebut lebih tenang dan lirih namun lebih terikat dalam satu waktu atau satu nada dalam temp yang sama dan tidak melambat. Dibawah ini adalah contoh gambar dinamika pianissimo leggato pada birama 20-28. 


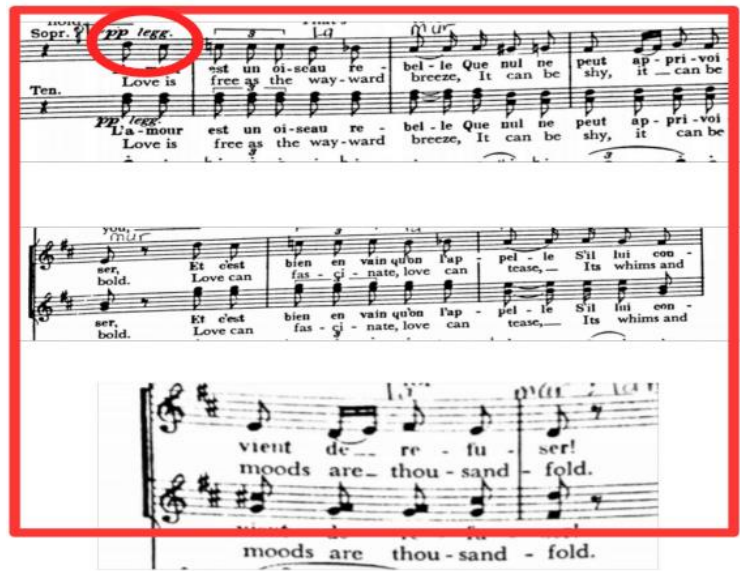

Gambar 8. Dinamika pianissimo legato (pp legg) pada birama 20-28 oleh paduan suara dan dilakukan repeat di birama 80-88. Sumber gambar : G.

Schimer, Inc. Ciptaan : George Bizet.

Selain itu, Habanera juga memiliki dinamika yang keras pada beberapa birama terterntu contoh seperti biara Forte (f). Dinamika ini memiliki frekuensi yang cenderung keras dan tegas, pada partitur lagu Habanera yang digunakan oleh narasumber utama, Forte berada pada birama 25-26 (vokal utama versi yang digunakan oleh narasumber itu sendiri), 36-37 (paduan suara), 43-44 (vokal utama dengan paduan suara di birama 44), 5253 (paduan suara), 56-57 (paduan suara), 59-60 (vokal utama dengan paduan suara di birama 60), 85- 86 (vokal utama versi yang digunakan oleh narasumber itu sendiri), 96-97 (paduan suara), 100-101 (paduan suara), 112-113 (paduan suara), 119-120 (vokal utama dengan paduan suara di birama 120). Dinamika ini cenderung dipakai oleh backing vocal paduan suara dari vokal utama, Heny Janawati menggunakan tambahan dinamika forte ini untuk memperindah lagu di birama 25-26 dan birama 85-86 di lirik 'L'amour. Berikut dibawah ini adalah contoh gambar birama 25-26 yang ditambah dinamika Forte oleh narasumber utama.

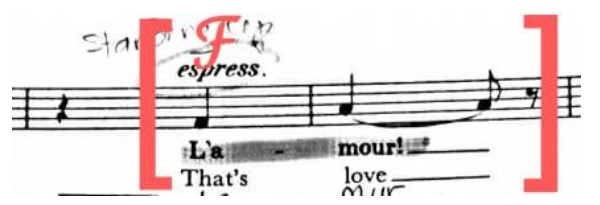

Gambar 9. Dinamika Forte pada birama 25-26 dengan ekspresi (look sensualy). Sumber gambar :

G. Schimer, Inc. Ciptaan : George Bizet
Pada birama 36-37 terdapat dinamika Forte menurut partitur Habanera bertujuan untuk menjadi backing vocal dalam pengulangan dari vokal utama dengan ekspresi yang seolah meyakinkan cerita yang ada pada lagu yang dinyanyikan.

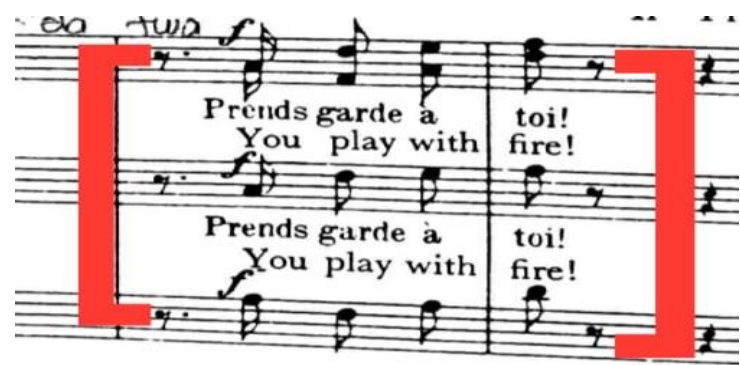

Gambar 10. Dinamika Forte di birama 36-37 yang digunakan oleh paduan suara. Sumber gambar : G.

Schimer, Inc. Ciptaan : George Bizet

Dinamika Forte juga terletak pada birama 59-60 di vokal utama sesuai dengan partitur Habanera yang bertujuan menghentak dan menjadikan klimaks dinamika akhir dari chorus menuju pada bagian ke dua. Lalu disusul dengan dinamika Forte di akhir birama untuk mendukung hentakan klimaks dari vokal utama yang akan menuju bagian ke dua.

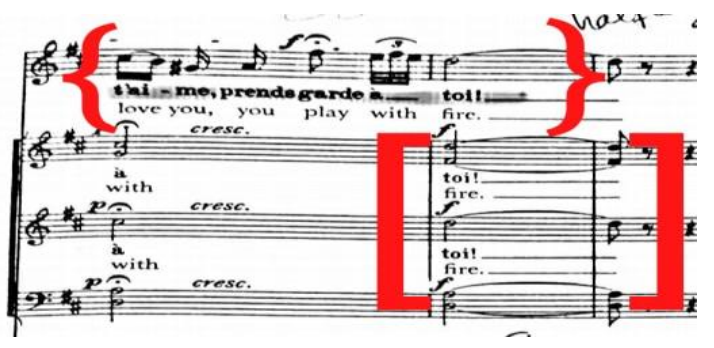

Gambar 11. Dinamika Forte berada di birama 5960 pada vokal utama dan berada di birama 60 pada paduan suara. Sumber gambar: G. Schimer, Inc. Ciptaan : George Bizet

Letak dinamika Forte di birama-birama selanjutnya partitur lagu Habanera yang digunakan oleh narasumber utama ini cenderung sama dengan contoh beberapa gambar diatas karena adanya repeat (pengulangan).

Terdapat anak dinamika dari Forte yaitu Mezzoforte (mf), dinamika Mezzoforte merupakan dinamika sedikit keras, Dinamika ini terletak pada birama 44-52, pada birama 52 hanya berada di notasi awal pada paduan suara, birama 104-112, birama 112 hanya ada di notasi awal. Mezzoforte yang bertujuan untuk 
mengekpresikan vokal utama bercerita soal Carmen yang selalu ingin bebas tak mengenal hukum dan berekpresi santai namun angkguh. Dinamika tersebut terletak pada chorus di notasi awal setelah adanya tanda istirahat, di interpretasikan dari birama 44 hingga birama 52. Berikut dibawah ini contoh gambar letak dinamika Forte pada chorus di birama yang disebutkan.

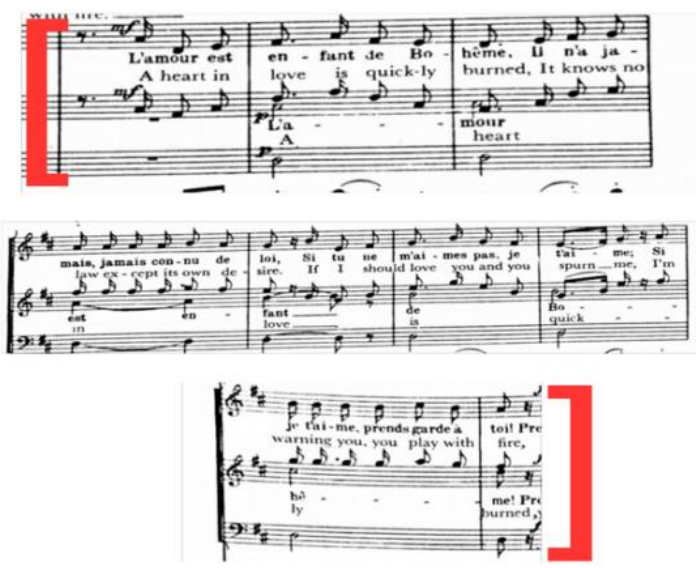

Gambar 12. Letak dinamika Mezzoforte di birama 44-52 notasi awal oleh paduan suara. Sumber gambar : G. Schimer, Inc. Ciptaan : George Bizet

Lagu Habanera juga memiliki dinamika Cresscendo (<) yang merupakan sebuah perubahan dinamika nada mulai dari lembut ke keras secara bertahap, menjadikan nada atau suara lebih nyaring. Sesuai partitur lagu Habanera yang digunakan oleh narasumber utama, dinamika ini ada pada birama 25-26, 5758, 85-86, 102 (nada awal)-103, 117(nada akhir)-118(nada awal), lalu ada penambahan dinamika Cresscendo oleh Heny Janawati di birama 44 untuk memperindah dan mempermanis bagian tersebut. Berikut adalah contoh salah satu gambar letak dinamika Cresscendo yang menggunakan tanda $(<)$ maupun tanda "cressc" (wawancara Janawati 4 Desember 2020). Pada birama 25-26 terdapat dinamika Cresscendo menurut partitur lagu Habanera yang bertujuan untuk menghaluskan perpindahan (bridge) Mezzoforte ke Forte agar terdengar lebih halus. Berikut adalah contoh gambar letak dinamika Cresscendo pada birama 25-26.

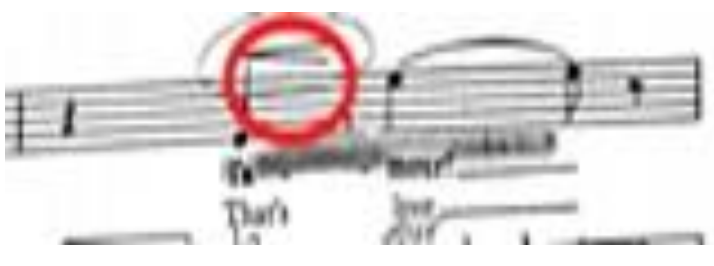

Gambar 13. Letak dinamika Cresscendo dengan tanda $(<)$ terletak pada birama 25-26. Sumber gambar: G. Schimer, Inc. Ciptaan : George Bizet

Pada birama 57-58 terdapat dinamika

Cresscendo dengan simbol "cressc" yang bertujuan untuk memberi jembatan yang halus pada klimaks dari akhir pengulangan lagu pada chorus. Contoh letak dinamika Cresscendo pada birama 57-58 pada gambar dibawah ini.

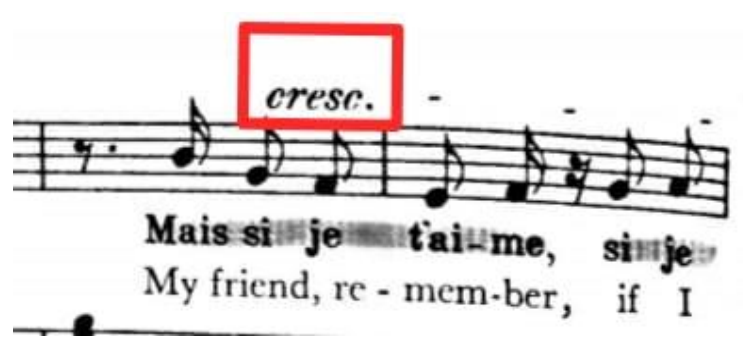

Gambar 14. Letak dinamika Cresscendo dengan tanda (cresc.) terletak pada birama 57-58. Sumber gambar : G. Schimer, Inc. Ciptaan : George Bizet

Pada birama 44 terdapat dinamika Cresscendo yang ditambah oleh narasumber utama dengan tujuan untuk memperjas artikulasi saat mencapai klimaks sebelum menuju pada bagian repeat atau pengulangan agar tidak secara langsung menhentak kasar istiilah pengganti dinamika Forte pada birama tersebut. Contoh dibawah ini adalah gambar letak dinamika Cresscendo yang ditambah oleh narasumber utama yaitu Heny Janawati yang menjadi vokal utama pada lagu ini.

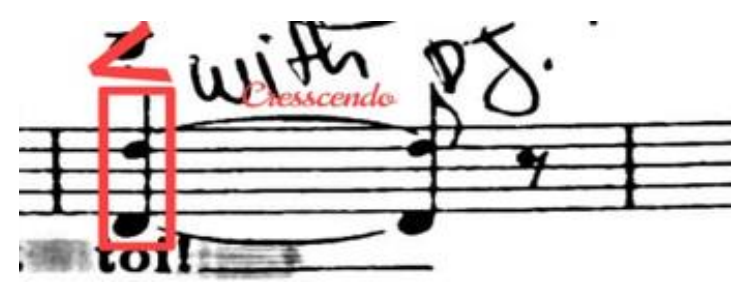

Gambar 15. Letak dinamika Cresscendo yang dibuat oleh narasumber pada birama 44. Sumber gambar: G. Schimer, Inc. Ciptaan : George Bizet

Selain Cresscendo, lagu Habanera juga terdapat Decresscendo (>). Yang merupakan 
kebalikan dari Cresscendo. Memiliki perubahan dinamika dari keras ke lembut secara bertahap. Tanda dinamika ini ditambah oleh Heny Janawati di birama 37-38 dan dilakukan repeat atau pengulangan pada birama 97-98 lalu ada juga di birama 41 dan birama 43. (wawancara, Janawati 4 Desember 2020) tujuannya agar lagu terlihat lebih indah dan manis. dilakukan pengulangan yang sama pada birama 97-98. Dinamika ini ditambahkan oleh narasumber utama dengan tujuan untuk menambah kesan feel look sensually pada pengulangan dari birama 32 dan menginterpretasikan sifat Carmen sebagai seorang perempuan gipsy. (Janawati, 4 Desember 2020) Contoh gambar dibawah ini dinamika Decresscendo birama 3738 dengan pengulangan di birama 97-98.

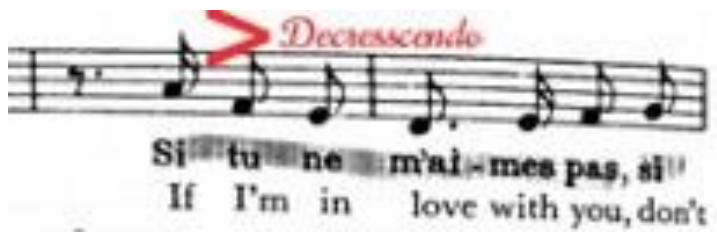

Gambar 16. Letak penambahan dinamika Decresscendo pada birama 37-38 oleh narasumber utama dan dilakukan repeat atau pengulangan pada birama 97-98. Sumber gambar: G. Schimer, Inc.

Ciptaan : George Bizet

Lagu Habanera juga memiliki istilah dinamika Portamento yang artinya dua nada yang berlainan disambung dengan menggeser suara secara santai dari nada rendah ke nada tinggi teknik dinamika ini hampir sama dengan Glissando. Dinamika Portamento berada pada birama 16 dan birama 72 dimana pada biramabirama tersebut memiliki tangga nada kromatik disetiap notasinya. Berikut adalah contoh gambar letak dinamika Portamento dari partiture lagu Habanera yang digunakan oleh narasumber utama:

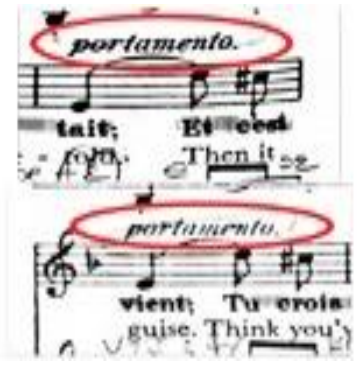

Gambar 17. Letak dinamika Portamento pada birama 16 di lingkaran atas dan birama $72 \mathrm{di}$ lingkaran bawah. Sumber gambar: G. Schimer, Inc. Ciptaan : George Bizet
Selain itu, ada istilah intonasi dalam interpretasi. Intonasi dalam musik khususnya di vokal adalah tingkat sulit ketepatan tinggi rendahnya nada atau suara yang dalam di setiap jumlah suku kata memiliki penekanan yang berbeda-beda. Menurut Heny Janawati, dalam lagu Habanera ini tingkat kesulitannya bukan pada nada tinggi atau nada rendahnya namun pada nada kromatik minornya yang pada akhirnya berubah menjadi mayor lalu ke minor lagi dengan teknik kromatik. Jika sedikit terbunyi nada yang tidak tepat akan sangat terdengar tidak sesuai dengan peraturan pada partiture yang dinyanyikan. Tanda kromatik terletak di birama 4-20 dengan pengulanganm di birama 64-80.

Bentuk Penyajian Lagu Habanera Dalam Opera Carmen Karya George Bizet Oleh Heny Janawati

Bentuk penyajian memiliki konteks lebih luas daripada interpretasi, mimiliki stage directing yang mengatur berjalannya sajian musik vokal. Setiap bentuk mengandung makna, pesan atau amanat yang diyakini penciptanya untuk kemudian disampaikan kepada orang lain. Pemikiran, perasaan, dan suasana hati sang pencipta dinyatakan dalam bentuk yang sesuai dengan isi karya seni tersebut (Sumardjo, 2000: 116). Suatu contoh dalam concerto solo vokal dengan orchestra maupun opera dengan orchestra diatur bagaimana letak piano, letak orchestra, letak properti dan harus memahami dimana letak berdirinya pemain pada adegan apa jika didalam opera, lalu bagaimana arahan masuk dan keluarnya pemain didalam panggung, bentuk penyajian berhubungan dengan stage manager, lighting, sound system, bagaimana konsepnya dan siapa konseptornya (yang membuat konsep) secara keseluruhan (Janawati, 4 Desember 2020). Sedangkan menurut teori Kamus Besar Bahasa Indonesia, bentuk penyajian dapat diartikan dapat diartikan sebagai cara menyampaikan suatu pagelaran atau pertunjukan yang digunakan sebagai alat komunikasi untuk menyampaikan, menghidangkan menyajikan atau dengan kata lain, pengaturan penampilan suatu pesan tertentu dari pencipta kepada masyarakat (Poerwardaminto, 1989).

Dalam bentuk penyajian opera memiliki keunikan sendiri dalam menyajikannya. opera merupakan drama musik yang didalamnya terdapat sandiwara serta dari berbagai pemeran 


\section{Interpretasi dan Bentuk Penyajian Lagu "Habanera" dalam Opera Carmen Karya Geroge Bizet Oleh Heny Janawati}

latar yang berbeda, yang kemudian dipersiapkan dan ditampilkan dalam bentuk unsur musik dan musik vocal (Sinaga, 2018 : 88). Memahami pemeran latar yang memiliki karakter yang berbeda-beda, dalam penelitian ini, karakteristik Carmen dalam lagu Habanera, didalam lagu ini, Carmen memiliki sifat yang angkuh akan kecantikannya kepada seluruh tentara-tentara yang ada disekelilingnya, Carmen berjalan diantara tentara dan para gadis pekerja pabrik rokok lainnya. Seluruh tentara terpesona oleh Carmen dan tidak lepas pandang dari seorang Carmen. Gadis lainnyapun iri dan kemudian terjadi pertengkaran setelah itu karena ulah Carmen. Ada satu hal yang membuat Carmen heran di depan sana, ada seorang lelaki yang diam, mendunduk, memegang rantai dan dia adalah satu-satunya lelaki yang tidak memandang Carmen sama sekali dan hanya diam. Lelaki tersebut bernama Don Jose, Don Jose adalah seorang prajurit, Don Jose lelaki yang santun dan baik. Disinilah pertemuan antara Carmen dan Don Jose dimulai. pada saat Carmen mengarahkan pandangan kepada Don Jose dan berusaha untuk menghampiri Don Jose, Don Jose hanya bisa membuang wajah dan berusaha agar tidak memandang Carmen, karena itu juga Carmen semakin penasaran olehnya. Lagu Habanera ini dinyanyikan Carmen dengan santai dan bernarasi layaknya tarian Havana namun memiliki makna cinta yang penuh tekateki (wawancara, Janawati 4 Desember 2020). Sama halnya dengan bunyi teori "Several points are worth mentioning regarding the followimg duo between Carmen and Jose. The idea comes from the novella, where Carmen follows gypsy tradition by dancing a romalis (Bizet George, 2018). Kemudian pelaksanaan Opera Carmen. Opera Carmen karya komposer asli Perancis yaitu George Bizet ini ditampilkan pertama kali di Indonesia dalam rangkaian perayaan 20 tahun Batavia Madrigal Singers yang dipersembahkan atau di produksi oleh The Resonanz Music Studio selaku Lembaga Pendidikan musik di bawah pimpinan Avip Priatna yang jadi Conductor dalam sajian Opera Carmen yang diselenmggarakan ini dan di dukung oleh Djarum Foundation yang digelar di Gedung Ciputra Artpreneur dan memiliki alamat di Jl. Prof. Dr. Satrio Kav, 3-5 Ciputra World 1, Level 13 Jakarta Selatan pada tanggal pelaksaan yaitu 16 April 2016 pukul 16:30 WIB dan 17 April 2016 pukul 16:00 WIB. Jos Groenier adalah sutradara dalam penyajian opera ini di Indonesia yang mengarahkan pemeran untuk sesuai dengan naskah aslinya. Opera ini juga melibatkan koor dalam jumlah besar seperti Batavia Madrigal Singers dan The Resonanz Children's Choir. Dalam Opera Carmen pertama di Indonesia ini, yang membuat menarik lagi adalah dengan dihadirkannya narator berbahasa Indonesia yaitu Happy Salma yang bertujuan membantu penonton untuk menikmati opera ini. Opera Carmen ini melibatkan pelatih vokal berdarah Jepang dan Hawai yaitu Brian Masuda yang melatih seluruh penampil untuk pelafalan naskah Carmen yang berbahasa Perancis khususnya pada peran utaman yaitu Carmen yang diperankan oleh Heny Janawati. Opera Carmen ini di iringi oleh Jakarta Concert Orchestra dengan Conduct Avip Priatna selama opera berlangsung.

Dalam penelitian ini, sajian iringan lagu Habanera oleh Heny Janawati dalam pentas ini menggunakan flute untuk filler bernuansa sopran. Selain itu oboe menjadi salah satu alat pengiring lagu Habanera yang digunakan untuk filler alto, clarinet, clarinet juga ikut serta mengiringi lagu Habanera yang digunakan untuk filler tenor, bassoon digunakan untuk filler bariton., horn/ french horn digunakan sebagai filler bass. Selanjtnya ada alat musik perkusi yaitu timpani digunakan untuk memberikan dinamika disetiap birama tertentu, bass drum menjadi salah satu pengiring ritme lagu Habanera yang digunakan untuk tempo awal setiap pergantian struktur lagu, tamborin digunakan saat paduan suara bernyanyi, tamborin menjadi tempo atau tepukan disetiap nada atau lirik backing vocal, triangle juga punya peran penting untuk mengiringi berlangsungnya lagu Habanera sama seperti tamborin alat musik ritmis ini juga menjadi tempo atau tepukan di setiap nada atau lirik oleh paduan backing vocal paduan suara. Lagu Habanera juga menggunakan iringan alat musik full string yang terdiri dari Violin, Viola, Cello, Contrabass. Violin digunakan sebagai filler sopran/melodi utama, viola digunakan sebagai filler alto, cello digunakan sebagai filler tenor, contrabass digunakan untuk filler bass. .Pada bentuk penyajian lagu Habanera dalam Opera Carmen ini juga memiliki dimensi Setting Saat Lagu Habanera Berlangsung. Drama/Opera memiliki beberapa babak atau adegan yang memiliki setting berbeda tetapi tetap dalam satu 
panggung karena semua adegan dilaksanakan di panggung, maka panggung harus bisa menggambarkan setting yang dikehendaki. Panggung harus bisa menggambarkan tempat dan suasana adegan itu terjadi, penggambaran setting sering berubah-ubah hampir setiap adegan. Beberapa adalah jenis-jenis setting yang ada dalam dimensi panggung

\section{Setting Tempat}

Dalam Opera Carmen yang dibahas, karena keterbatasan di Indonesia tidak memungkinkan seperti sajian opera yang asli (tradisonal) di Eropa maka bernyanyinya memakai kondensor atau mic yang menggantung, dibawah panggung, dan headset untuk setiap pemain utnuk menghandle suara dipanggung, lalu memakai LCD dan multimedia. Setting tempat panggung dalam sajian Opera Carmen ini didalam panggung ada panggung yang membentuk Later $U$ ditengah panggung tersebut ada pengiring musik yaitu Orchestra beserta Konduktornya. Berikut adalah contoh Setting tempat panggung Opera Carmen dalam penelitian ini:

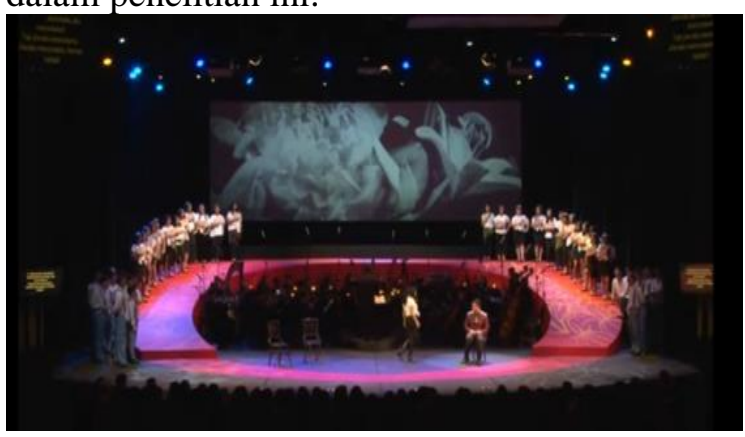

Gambar 18. Bentuk Setting tempat dari panggung, tempat pemain opera dan pemain musik, serta tempat penonton pada saat lagu Habanera dalam Opera Carmen berlangsung. Sumber Gambar : Youtube Jakarta concert orchestra.

\section{Setting Waktu}

Dalam sajian Opera Carmen ini dilaksanakan pada tahun 2016 di tanggal 16 dan 17 April di musim kemarau pada hari Sabtu dan Minggu jam 16:30 WIB pada 16 April 2016 dan 16:00 WIB pada 17 April 2016. Lagu Habanera dimainkan atau dinyanyikan oleh pemeran Carmen yaitu Heny Janawati pada babak pertama di adegan ke lima.

\section{Setting Peristiwa}

Dalam sajian Opera Carmen ini, cerita opera ini memiliki perilaku atau kebiasaan hidup yang bebas akan percintaan dan hukum dalam masyarakatnya terutama pada pemeran utamanya yaitu Carmen, memiliki keyakinan kepada Yahudi di jaman romantik, cara berfikir maupun sikap masih begitu liar terutama pada cerita percintaan untuk Carmen sendiri sebagai pemeran utama. Berikut adalah contoh gambar setting peristiwa saat Carmen bernyanyi lagu Habanera:

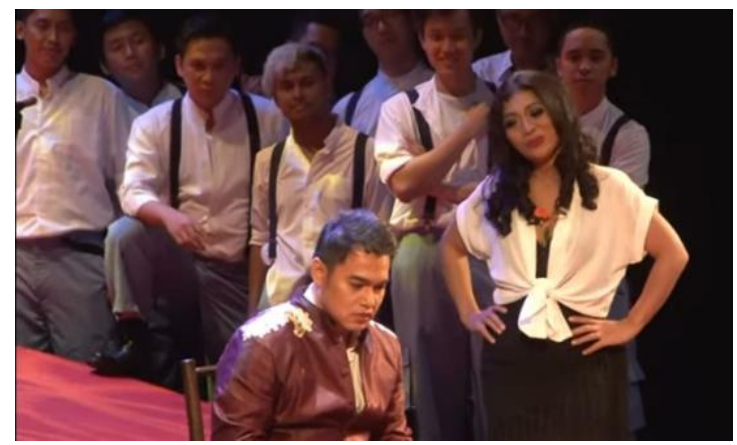

Gambar 19. Setting Peristiwa saat Carmen bernyanyi lagu Habanera. Sumber Gambar : youtube Jakarta concert orchestra.

Penyajian lagu Habanera memiliki tata cahaya, keseluruhan, lighting yang digunakan adalah spot light putih untuk menyorot penyanyi utama, mengikuti arah penyanyi utama itu berjalan, lighting kiri dan lighting kanan berwarna kuning dan biru untuk paduan suara perempuan disebelah kanan dan sebelah kiri untuk pemeran pria, lighting putih di atas untuk menyorot ke depan dan menyorot Don Jose yang ada dipinggir kiri depan, blacklight ditengah untuk para pemain orchestra yang hanya menggunakan cahaya kecil kuning di standpart masing-masing dari pemain, overall lighting merah, alur lighting selama lagu Habanera berlangsung menyala dan tidak berpindah tempat walaupun penyanyi utaman berjalan berpindah tempat karena sudah banyak pencahayaan di panggung kecuali pada pemain orchestra yang ada ditengah panggung.

Dalam Opera Carmen tak luput juga dengan ciri khas pada tata rias dan busana khususnya pada saat lagu Habanera berlangsung seperti tata rias dan busana oleh vokal utama dan paduan suara maupun pemeran lain yang ada dipanggung pada saat lagu Habanera berlangsung. Penyanyi utama Habanera yang berperan menjadi Carmen berganti busana sebanyak tiga kali yang artinya Carmen memakai tiga kostum secara bergantian dari awal mulai Opera hingga akhir Opera, pada 
Opera ini baju yang dikenakan lebih modern dan bervariasi dari Carmen yang asli. Namun disini fokus dengan rias dan busana lagu Habanera. Lagu Habanera termasuk di bagian pertama dan pada bagian pertama, Carmen menggunakan rias tajam pada eyeshadow hitam abu, lipstick merah terang dan blush on terang untuk menambah ketajaman make-up Carmen, serta rambut panjang bergelombang yang terurai. Busana casual dengan rok mini hitam rumbai-rumbai, kemben hitam dengan kain putih yang dipakai ditubuh Carmen dan di ikat di perut Carmen dan membawa bunga mawar, memakai sepatu boot hitam sepanjang bawah lutut dengan stocking berwarna hitam untuk paduan suara yang ada dipanggung selain pemain orchestra yang memakai busana identik hitam gelap, paduan suara sopran memakai rias busana casual yang hampir sama dengan Carmen namun berbedabeda style sedangkan paduan suara tenor dan bass memakai baju casual atasan identik putih dengan memakai suspender dan celana panjang dengan style yang berbeda-beda sedangkan pemeran Don Jose yang berada dipanggung duduk dikursi pada saat lagu Habanera berlansgug memakai busana lebih classy jas berwarna coklat dan celana panjang untuk menggambarkan seorang prajurit dalam opera tersebut. Berikut adalah contoh gambar keseluruhan tata rias busana pemeran atau pemain Opera Carmen saat lagu Habanera berlansung:
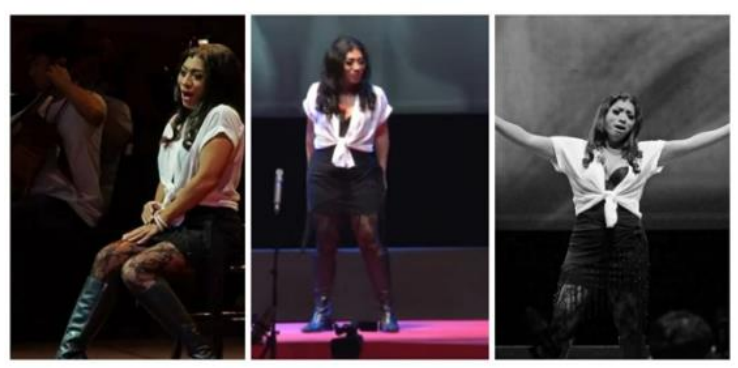

Gambar 20. Tata Rias Busana Modern Carmen Saat Lagu Habanera Berlangsung Oleh Heny Janawati. Sumber Gambar : Heny Janawati.

Pada gambar diatas menunjukkan moment saat Heny Janawati menampilkan lagu Habanera dalam Opera Carmen menjadi pemeran Carmen di Jakarta dengan memakai busana casual dengan rok mini hitam rumbairumbai, kemben hitam dengan kain putih yang dipakai ditubuh Carmen dan di ikat di perut
Carmen dan membawa bunga mawar, memakai sepatu boot hitam sepanjang bawah lutut dengan stocking berwarna hitam.

\section{SIMPULAN}

Berdasarkan hasil penelitian dan pembahasan ini, maka dapat disimpulkan bahwa lagu Habanera memiliki tingkat kesulitan yang tidak semua orang sanggup menyanyikannya. Seorang penyanyi mezzo-soprano Indonesia, Heny Janawati menginterpretasikan dan menyajikan lagu ini dengan baik. Interpretasi dalam konteks peneitian ini ialah upaya penyanyi dalam menyampaikan pesan dari lagu yang dinyanyikan kepada para penonton. Begitupun interpretasi yang dilakukan oleh Heny Janawati saat menyanyikan lagu Habanera dengan pembawaan karakter tokoh Carmen yang liar namun masih memiliki kebaikan dan inner beauty saat menampilkannya. Teknik interpretasi yang dilakukan Heny Janawati yakni meliputi pengembangan variasi ide penyanyi untuk menyampaikan partitur tersebut dan pengembangan partitur itu sendiri sesuai keinginan komposer. Hal ini dilakukan karena setiap penyanyi dan komposer memiliki masingmasing ciri khas penghayatan dan penafsiran itu sendiri. Interpretasi tersebut mencakup: 1) struktur cerita lagu disetiap lirik atau libretto yang diinginkan komponis; 2) tempo; 3) dinamika; dan 4) intonasi. Semua hal tersebut harus diungkapkan sesuai keinginan komponis dan pengembangan dari penyanyi. Habanera memiliki tingkat kesulitan di setiap nada kromatiknya yang menuntut penyanyi harus menempatkan nada dengan benar. Habanera memiliki tempo Alegretto quasi Andantino dan memiliki dinamika piano ( $p)$, pianissimo ( $p p)$, mezzo-forte $(\mathrm{mf})$, crescendo $(<)$, decrescendo (>), terakhir adalah portamento.

Bentuk penyajian lagu Habanera oleh Heny Janawati memiliki konsep yang berbeda dari Opera Carmen yang ditampilkan di Eropa. Perbedaan tersebut seperti jumlah alat musik dan pemainnya, setting tempat, waktu dan peristiwa, tata cahaya (lighting), tata rias dan busana. Sehingga kesan secara keseluruhan bentuk penyajian Lagu Habanera memiliki konsep lebih modern daripada saat ditampilkan oleh Heny Janawati di Eropa.

\section{DAFTAR PUSTAKA}

Banoe, P. (2003). Kamus Musik. Kanisius.

Bizet George. (2018). Carmen. Alma Books.

Dankworth, A. (1978). "Music" dalam The 
Education of The Young Child (D. Fontana (ed.)). Open Books.

Dharmawanputra, B., Murbiyantoro, H., \& Karyawanto, H. Y. (2020, December). Vocal Class in Method Lecture During the Covid-19 Pandemic. In International Joint Conference on Arts and Humanities (IJCAH 2020) (pp. 805-809). Atlantis Press.

Hardjana, Suka. Corat Coret Musik Kontemporer Dulu dan Kini. Jakarta: Kerajasama Fond

Kertesz, E., \& Christoforidis, M. (2008). Confronting" Carmen" beyond the Pyrenees: Bizet's Opera in Madrid, 18871888. Cambridge Opera Journal, 79-110.

Nurcahyo, P. N. (2018). Interpretasi Komposisi" Sukma" untuk Piano Solo Karya Budhi Ngurah (Doctoral dissertation, Institut Seni
Indonesia Yogyakarta).

Poerwardaminto. (1989). Kamus Besar Bahasa Indonesia (p. 862). Balai Pustaka.

Prier. (2011). Kamus Musik. Pusat Musik Liturgi.

Prier. (2017). Ilmu Bentuk Musik. Pusat Musik Liturgi.

Schoepp, K. (2001). The Internet Journal, 7 (2), 1-4. Reasons For Using Songs In The ESL/EFL Classroom.

Sinaga, T. Dasar-Dasar Teknik Bernyanyi Opera. Gondang: Jurnal Seni dan Budaya, 2(2), 79-89.

Sugiyono. (2017). Metode Penelitian Kuantitatif Kualitatif $R \& D$. Alfabeta.

Sumardjo, Jakob. 2000. Filsafat Seni. Bandung: ITB 